\title{
LOCAL APPLICATION OF LOW POWER MILLIMETER INDUCES PAIN RELIEF IN CHRONIC PANCREATITIS ALLOWING PHYSICAL REHABILITATION: A CASE REPORT
}

KEY WORDS: pain, chronic pancreatitis, millimetric waves.

\section{Prof Jean-Claude Debouzy*}

\section{Crouzier, D.} Verdu-Negro $P$.

$7^{\text {th }}$ French Army Medical Center, Quartier Reyniès, 38760 Varces, France; Armed Forced Biomedical research Institute (IRBA), Non conventional threats Department, place V Andrée, 91233 Bretigny sur Orge cedex, France. *Corresponding Author Remedee Labs; 29 chemin du vieux chêne, 38240 Meylan, France.

Aims : to report effects of local exposure to low level millimetric waves on chronical pancreatitis (PCC) related pain. Chronic pancreatitis at the initial stages, is characterized by flare-ups of acute pancreatitis, and by recurrent and chronic pain which is the main clinical expression of the disease. Presentation of the case : We report the effects of low level electromagnetic wave in the millimetric frequency (MMW, $60 \mathrm{GHz}$, continuous wave) wrist exposure on PCC related typical epigastric pain (transfixing, triggered by any food intake), leading to extreme weight loss by apprehension of food intake. Results: MMW exposure resulted in almost complete pain relief and antalgic drug suppression, this allowing weight recovery and active rehabilitation. Discussion : beside natural PCC evolution, different mechanisms involved in such pain release: endorphins and/or parasympathetic pathways, neuro inflammation are presented. Conclusion : low level millimetric exposure could be proposed for PCC, and other chronical digestive painful diseases to overcome pain and thus facilitate clinical care or rehabilitation.

\section{INTRODUCTION}

Chronic pancreatitis (PCC) is defined as a chronic inflammation of the pancreas leading in the long term to more or less complete destruction of the pancreatic gland. Clinically, the excretory ducts as well as the tissue (exocrine) are affected, with the term fibrosis and disseminated calcifications associated with endocrine tissue damage (and therefore diabetes). The course is often complicated by painful attacks related to the formation of pseudocysts or compressions of the main bile duct (acute pancreatitis). They can become complicated by a pancreatic abscess or cause haemorrhage or even rupture in a nearby hollow organ or in the peritoneal cavity ${ }^{1,2}$. The major sign is in all cases pain, which is readily syncopal and triggered by food intake against a background of chronic pain. Two main mechanisms are proposed to explain these pains ${ }^{3,4}$ : either hyper pressure, linked to fibrosis or obstruction of the pathways of excretion, and / or a neurogenic origin linked to a fibro-inflammatory process including the pancreatic nerves. The expression of pain varies greatly from one patient to another, in duration (periodic, constant, by crisis ...) in intensity and duration (from a few seconds, a day or even more). The long-term evolution (15-20 years) is towards the more or less complete disappearance of pain, while the manifestations linked to the destruction of pancreatic tissue (diabetes, calcifications, external pancreatic insufficiency) are in the foreground. The clinical case presented here represented the evolution over 10 years of a PCC of alcoholic origin, accompanied by painful outbreaks linked to food intake; the result being avoidance of food leading to undernutrition.

Besides surgical interventions and substitution treatments, different pharmacological approaches to control pain failed ans . Finally, the patient acquired a commercial millimetre wave transmitter initially designed for well-being. (millimetre machine, MD) in an attempt to at least partially overcome the pain and allow nourishment. The basic principle of this system uses the analgesic properties of millimeter waves (in the $30-90 \mathrm{GHz}$ bands), widely described in the last decade of the 20 th century ${ }^{5,6}$ and more recently reviewed in some recent studies and reviews. The basic mechanism relied on endorphin secretions from the CNS, itself triggered by a peripheral stimulus(i.e. MMW) applied to the median nerve of the wrist ${ }^{7}$

In practice, as described elsewhere, the miniaturized 106 transmitter was mounted on a bracelet intended to be worn like a watch (see figure 1): "This device emits a continuous electromagnetic wave of $60 \mathrm{GHz}$ at a power density of $14 \mathrm{~mW} / \mathrm{cm}^{2}$ on $2 \mathrm{~cm}^{2}$ of skin surface on the palmar face of the wrist, 2 sessions of 30 minutes per day), that is in close contact with the median nerve ". We report here the management of pain by the patient and the evolution his general condition.

FIGURE 1:The MD, mounted as a watch strap. Arrows (2-3) show the $2 \mathrm{~cm} 2$ rectangular antennae along the path of the median nerve; the battery is placed on the other side of the bracelet (1).

\section{Photo:remedeeLabs}

\section{PRESENTATION OFTHE CASE}

Mr. JeremyV... is currently 40 years old. At the initial stage of his disease, he had as a history an endobrachioesophagus without real dysplasia and a small hepatic angioma on a known ground of ethylo-tobacco intoxication (15 cigarettes / day). Neither the 2008 examinations carried out on atypical epigastralgia nor those carried out on an unlabelled peritoneal effusion showed no abnormality at the hepatic or pancreatic level, although weight loss was already present. The identification of his disease (PCC) itself began in 2010 with severe abdominal pain triggered by alcohol and food intake, leading to further weight loss (see Table I); The tomodensitometric examination then revealed calcification at the level of the head of the pancreas and a nodule on the caudal part. Fundic vesicular microlithiasis was still being 
discussed. The diagnosis of chronic pancreatitis was confirmed in 2011, when three cysts of the head of the pancreas were identified (the largest measured $4 \mathrm{x} 2 \mathrm{~cm}$ ).

TABLE I : TIME COURSE OF WEIGHT (BMI, SIZE 1m77) AND PAIN (VAS)

\begin{tabular}{|c|c|c|c|}
\hline date & circumstances & Weight (BMI) & VAS \\
\hline $\mathbf{2 0 0 8}$ & Epigastric pain & $\begin{array}{c}60 \text { to 50 } \\
\left(19 \_15.9\right)\end{array}$ & 3_5 \\
\hline $\mathbf{2 0 1 0}$ & Diagnosis & $45(14.4)$ & 5_6 \\
\hline $\mathbf{2 0 1 2 \_ 1 3}$ & $\begin{array}{c}\text { Abscess drainage_and stents } \\
\text { placement }\end{array}$ & $50(15.9)$ & 3 \\
\hline $\mathbf{2 0 1 5}$ & reactivation of pain & $45(14.4)$ & 6 \\
\hline $\mathbf{2 0 2 0}$ & Shortly after start MMW & $50(15.9)$ & 2 \\
\hline $\mathbf{6 / 2 0 2 0}$ & $\begin{array}{c}\text { Diabete/external pancreatic } \\
\text { function care }\end{array}$ & $55(17.5)$ & 2 \\
\hline
\end{tabular}

As the progress continues, the patient is placed on morphine sulphate (SKENAN (C) and the large pseudo-cyst prevents the evacuation of pancreatic secretions which cause dilation of the pancreatic tract upstream and biliary compression (IRM 2012). The attitude then had been to drain these cysts by placing French stents allowing drainage but leaving a caudal pancreatic stenosis and communication of the remaining cyst with the pancreatic duct. This intervention allowed pain sedation (VAS = 3) with morphine withdrawal and weight gain $(50 \mathrm{~kg})$. This state remains relatively unchanged apart from complications related to portal hypertension (lamina of ascites and varicose veins of the portal trunk (2017), and arteritis of the iliac arteries treated by stent (2019)), the painful paroxysms of the left hypochondrium (VAS $=5-6$ ) resumed in 2015, in the form of painful outbreaks (VAS $=5-6$ ) nocturnal or triggered by food intakes not relieved by morphine sulphate (SKENAN LP 30mg, GABAPENTINE 300 and AKTIKENAN @ 10mg on demand).

Although the results do not show clear inflammation, but disseminated caudal calcifications associated with a stenosis of the lower bile duct (MRI 2016. The weight then oscillates between 45 and $50 \mathrm{~kg}$ These pains were presented in the form of painful flashes / burns at the level of the left hypochondrium with epigastric irradiations, with a frequency several per minute to several per hour triggered by the recumbency and the position leaning forward. These manifestations which could last several hours or even several days in an intermittent mode persist until 2020, date on which he obtains, after failure of other paramedical means (STENT, quite effective but of unsuitable use) the MMW bracelet in the hope of improving his living conditions, sleep and general condition. of the balance sheet using the classic SF36 questionnaire (Short Form Survey:SF-36, (see table II) This confirms a repercussion especially on social functioning, pain, as well as on general condition and overall fatigue. The result of this use is a lasting sedation (for hours) of the pain after a few minutes of wearing the bracelet), and in fact, the frequency and intensity of the pain (burns) has gradually decreased. There was a reduction in the doses of analgesics (e.g. from $40 \mathrm{mg}$ to $10 \mathrm{mg}$ AKTISKENAN at night. The last painful flare, identified as acute pancreatitis, occurred in January 2020. The SF36 assessment carried out in the long term confirms this improvement, mainly relating to pain and social functioning (2021, type 1 diabetes remains an external pancreatic insufficiency in the process of equilibration, all allowing to consider a rehabilitation of the general condition.

FIGURE II : Score calculated from SF36 Before/after MIMW use

\begin{tabular}{|c|c|c|}
\hline Criterion & Before MMW & After MMW \\
\hline Pain & 37.5 & 50 \\
\hline Social functioning & 37.5 & 62.5 \\
\hline Energy/Fatigue & 25 & 40 \\
\hline Emotional Well-being & 80 & 80 \\
\hline General Heath & 20 & 20 \\
\hline
\end{tabular}

\section{DISCUSSION}

The observations presented here relate to the effects of local exposure to low-power millimetric radiation $(60 \mathrm{GHz}$, $14 \mathrm{~mW} / \mathrm{cm}^{2}$, continuous waves) on pain care for a patient with chronic pancreatitis. The emitting device, MD (Remedee (C) had been acquired and tested by the patient himself with the hope of obtaining relative pain relief, well-being, sleep and general health status. Hence some heath improvements were obtained by this means (see table 1), thus leading to calls for three types of comments:

I./ The natural evolution of a PCC: as conventionally accepted $^{8,9}$, results in more or less pain relief while the remaining clinical manifestations are directly related to diabetes and external pancreatic insufficiencies. In this particular case, the patient was still painful and presented unrelieved pain even under morphine treatment, this precluding normal feeding. MMW exposure overcame both pain and feeding avoidance, and allowed an earlier starting of the compensatory treatments(insulin and exocrine substitutes, CREON(C EUROBIOL()). Final result was an improvement in general health status, especially in view of the extreme thinness of the patient $(B M I=14.4,45 \mathrm{~kg})$. At the same time, sedation at the cost of a low pain constraint, and the improvement of the quality of life are a significant contribution as such.

ii/ Russian historical background : A former paper recalled ${ }^{10}$ that " $M M W$ hypoalgesia results from a local stimulation of peripherical cutaneous receptors leading, via nervous centripetal information to central nervous secretion of endorphins ${ }^{11,12,13}$.This hypothesis is supported by several experimental results and publications ${ }^{14}$ ". For example, Ziskin proposed that exposures to MMW $\left(61 \mathrm{GHz}, 10 \mathrm{~mW} / \mathrm{cm}^{2}, \mathrm{CW}\right)$ at low intensity, because of their low penetration low penetration (less than $1 \mathrm{~mm}$ ); could only reach the nerve endings ; their stimulation triggers a message using neurotropic pathway, via immunocompetent cells (Langherans cells, and keratinocytes), the final result is the secretion of intrinsic cerebral cytokines (endorphins), therefore of opioid neuromediators(this was ascertained by naloxone induced secretion production; naloxone is a specific endorphins inhibitor).

iii/ PCC pain physiopathology : the role of fibroinflammatory process involving the pancreatic nerves and their related neurotransmitters : beside obvious endorphinic role, what would be sympathic, parasympathetic, cholinergic contributions? Hence, besides the induced secretion of endorphins, the vague mixt tightly connects the digestive tract and the central nervous system. For instance, it exhibits anti inflammatory properties mainly by activating the corticotropic axis after an inflammatory stress ${ }^{15}$, and also by directly releasing acetylcholine from its efferent fibres ${ }^{16}$. Moreover vagal stimulation has been evoked for therapeutic use of inflammatory diseases such as intestine Crohn disease or rheumatoid polyarthritis ${ }^{17}$.

\section{CONCLUSIONS}

Use of a device intended for another use (well-being or sleep). The clinically most important finding of this case study is that This case reports a significant reduction of $\mathrm{PCC}$ related obtained after exposure to a low power millimetric wave emitter $(60 \mathrm{GHz} \mathrm{CW})$ mounted on a wrist ring, originally designed for well-being or sleep quality improvement. This was especially true on acute painful episodes related in particular to food intake. Pain relief allowed feeding and recovery of general health status. Whereas pancreas organic destruction was still present, the management of pancreatic secretion deficits has thus been greatly facilitated. With regard to the mechanisms involved in the hypoalgesia effect, the stimulation of endorphin secretion is evident. This way is probably not exclusive since tight connections exist between the digestive neurophysiologic environment and the central 
nervous system. , especially mediated by parasympathetic system. Finally, other chronical digestive painful diseases (Crohn disease, gastric ulcer, biliary pathologies ...) could take benefit, apart from the etiological medical care, from an improvement in their daily well-being.

\section{REFERENCES}

1. Maire F, Lévy P, Rebours V, Hammel P, Ruszniewski P. De la pancréatite chronique aux pancréatites chroniques. Gastroenterol Clin Biol.2009;33:725-36

2. https://www.fmcgastro.org/postu-main/archives/postu-2005-paris/ traitement-de-la-douleur-de-la-pancreatite-chronique/2005

3. Bonaz propriétés anti-inflammatoires du nerf vague : implications thérapeutiques en gastroentérologie, ALN Ed. «Hegel» 2015,3(3): 173-179.

4. Pellissier S, Dantzer C, Mondillon L, Trocme C, Gauchez AS, Ducros V, Mathieu N, Toussaint B, Fournier A, Canini F, Bonaz B., 2014, Relationship between vagal tone, cortisol, TNF-alpha, epinephrine and negative affects in Crohn's disease and irritable bowel syndrome. PLoS One, 10-9(9):el05328.

5. Simko M and Mattsson MA, 2019, 5G Wireless Communication and Health Effects-A Pragmatic Review Based on Available Studies Regarding 6 to 100 $\mathrm{GHz}$, Int.J. Environ. Res. Public Health, 16:3406-3429.

6. Usichenko TI, Herget HF, 2003, Treatment of chronic pain with millimetre wave therapy (MWT) in patients with diffuse connective tissue diseases: a pilot case series study,European Journal of Pain, 7(3) : 289-294.

7. Rodjavin MA, Ziskin MC,1998, Medical application of millimetre waves, Q J Med1998;91:57-66

8. https://www.fmcgastro.org/postu-main/archives/postu-2005-paris/ traitement-de-la-douleur-de-la-pancreatite-chronique/.

9. Maire F, Lévy P, Rebours V, Hammel P, Ruszniewski P. De la pancréatite chroniqueauxpancréatiteschroniques. Castroenterol Clin Biol 2009:33:725-36.

10. Debouzy JC, Crouzier D, Rech S and Bachelet Campagne C, 2021, Biomed J Sci \&Tech Res 236361-26365.

11. De Roulet A, Inaba K, Strumwasser A, Chouliara K, Lam L, et al. (2017) Severe injuries associated with skiing and snowboarding: A national trauma data bank study.JTrauma Acute Care Surg 82(4):781-786.

12. Rojavin MA, Radzievsky AA, Cowan A, Ziskin MC (2000) Pain relief caused by millimeter waves in mice: Results of cold-water tail flick tests.cInt J Radiat Biol 76(4):575-579.

13. Radzievsky AA, Gordiienko OV, Alekseev S, Szabo I, Cowan A, and al. (2008) Electromagnetic millimeter wave induced hypoalgesia: Frequency dependence and involvement of endogenous opioids. Bioelectromagnetics 29(4):284-295

14. Pakhomov AG, AkyelY, Pakhomova ON, Stuck BE, Murphy MR (1998) Current State and Implications of Research on Biological Effects of Millimeter Waves: A Review of the Literature. Bioelectromagnetics, 19(7):393-413.

15. Bonaz BL, Bernstein CN. Brain-gut interactions in inflammatory bowel disease. Gastroenterology 2013 Jan;144(1):36.

16. Pavlov VA, Wang H, Czura CJ, Friedman SG, Tracey KJ. The cholinergic antiinflammatory pathway: a missing link in neuroimmunomodulation. Mol Med 2003 May-Aug;9(5-8):125-34.he

17. Koopman FA, Schuurman PR, Vervoordeldonk MJ, Tak PP. Vagus nerve stimulation: a new bioelectronics approach to treat rheumatoid arthritis? Best Pract Res Clin Rheumatol2014 Aug;28(4):625-35. 